\title{
Biomarkers of systemic inflammation and depression and fatigue in moderate clinically stable COPD
}

\author{
Khaled Al-shair ${ }^{1 *}$, Umme Kolsum, Rachel Dockry', Julie Morris ${ }^{2}$, Dave Singh, Jørgen Vestbo ${ }^{1,3}$
}

\begin{abstract}
Introduction: COPD is an inflammatory disease with major co-morbidities. It has recently been suggested that depression may be the result of systemic inflammation. We aimed to explore the association between systemic inflammation and symptoms of depression and fatigue in patients with mainly moderate and clinically stable COPD using a range of inflammatory biomarkers, 2 depression and 2 fatigue scales.
\end{abstract}

Method: We assessed 120 patients with moderate COPD (FEV $1 \% 52$, men 62\%, age 66). Depression was assessed using the BASDEC and CES-D scales. Fatigue was assessed using the Manchester COPD-fatigue scale (MCFS) and the Borg scale before and after 6MWT. We measured systemic TNF- $\alpha$, CRP, TNF- $\alpha-R 1$, TNF- $\alpha-R 2$ and IL-6.

Results: A multivariate linear model of all biomarkers showed that TNF- $\alpha$ only had a positive correlation with BASDEC depression score $(p=0.007)$. TNF- $\alpha$ remained positively correlated with depression $(p=0.024)$ after further adjusting for TNF- $\alpha-R 1, T N F-\alpha-R 2,6 M W D, F E V_{1} \%$, and pack-years. Even after adding the MCFS score, body mass and body composition to the model TNF- $\alpha$ was still associated with the BASDEC score $(p=0.044)$. Furthermore, patients with higher TNF- $\alpha$ level $(>3 \mathrm{pg} / \mathrm{ml}, \mathrm{n}=7)$ had higher mean CES-D depression score than the rest of the sample $(p=0.03)$. Borg fatigue score at baseline were weakly correlated with TNF- $\alpha$ and CRP, and with TNF- $\alpha$ only after 6MWT. Patients with higher TNF- $\alpha$ had more fatigue after 6MWD ( $p=0.054)$.

Conclusion: This study indicates a possible association between TNF- $\alpha$ and two frequent and major co-morbidities in COPD; i.e., depression and fatigue.

\section{Introduction}

COPD is a chronic inflammatory disease with systemic manifestations such as muscle wasting, depression and fatigue [1]. Systemic manifestations of COPD may significantly affect patients' quality of life and the prognosis of the disease [1]. It has been suggested that systemic manifestations may be related to systemic inflammation in COPD $[2,3]$.

Depression is a major comorbidity in COPD; it is associated with poor functional performance [4], significant impairment in health status and high mortality [5]. Fatigue is one of the most prominent disabling

\footnotetext{
* Correspondence: alshair02@yahoo.com

'University Of Manchester, Medicines Evaluation Unit, NIHR Translational Research Facility, Manchester Academic Health Sciences Centre, University Hospital Of South Manchester Foundation Trust, Wythenshawe, Manchester, UK

Full list of author information is available at the end of the article
}

symptoms in COPD [6]. It is strongly associated with depression [7], decline in daily functional activity [6], and substantial impairment in quality of life [8].

The association between symptoms of depression and fatigue and systemic inflammation has been examined in depth in healthy individuals and in illnesses such as coronary heart disease (CHD) [9-11]. In COPD, patients with more systemic inflammation as well as more depression or fatigue have been shown to be less physically active and more exercise intolerant $[4,6,12]$. Recently, Barnes and Celli have speculated that depression may correlate with systemic inflammation [13] and to date no study has addressed this.

We aimed to explore the association between systemic inflammation and symptoms of depression and fatigue in patients with mainly moderate and clinically stable COPD using a range of inflammatory biomarkers, two depression scales and two fatigue scales. 


\section{Methods \\ Study subjects}

The subjects enrolled in this study were 120 clinically stable patients enrolled from outpatient clinics and advertisements. More information on the recruitment, inclusion and exclusion criteria, and patients' demographic data has been described previously [4]. Briefly, all patients had COPD according to GOLD [14] and had been clinically stable for at least 4 weeks. Patients with exacerbations in the last 4 weeks were either rescheduled or excluded. We excluded patients with current or recurrent symptomatic ischemic heart disease, congestive heart disease, cerebrovascular disease, dementia, lung cancer, known psychiatric illness, maintenance treatment with systemic corticosteroids (oral, parenteral), active tuberculosis, inflammatory bowel syndrome or insulindependent diabetes mellitus. All participants gave written informed consent to participate in the study, and the South Manchester Research Ethics Committee had approved the study (Reference number 05/Q1402/41).

\section{Assessments}

For assessment of depression, two instruments were used: The Brief Assessment Schedule Depression Cards (BASDEC) and the Centre for Epidemiological Study on Depression (CES-D) Scale $[15,16]$. Both of the scales have been frequently used in assessing depression in COPD [17-19]. The impact of fatigue was assessed using our Manchester COPD fatigue scale (MCFS) which has a high level of validity and reliability [7]. It measures total fatigue as well as dimensional assessment of physical, cognitive and psychosocial fatigue. The total score ranges from 0-54, the higher the score the more the fatigue. We also assessed the intensity of fatigue before and after a 6 minute walk test (6MWT) using the Borg scale [20]. Patients rated their feeling by the selection of one option, ranging from $0-12$, with 0 meaning no fatigue and 12 meaning extreme fatigue intensity. We used the Bioelectrical Impedance Analysis (BIA) to measure body composition by (Bodystat Ltd, Douglas, UK). Spirometry was done according to the ATS/ERS Standardisation Guideline [21] using a Jaeger MasterScreen spirometer (Jaeger Ltd, Hoechberg, Germany). Functional performance was measured using the 6MWT according to the ATS guideline [22]. Health Status was measured by the St George's Respiratory Questionnaire (SGRQ) [23].

\section{Systemic biomarkers measurement}

Venous blood samples were obtained before the exercise test to measure the required biomarkers. The samples were centrifuged and allocated in well-marked tubes with patients' initials, date of donation, database number and type of sample (plasma or serum), and samples were immediately stored at $-80^{\circ} \mathrm{C}$ until analysis. Plasma
TNF- $\alpha$ and serum IL- 6 was measured by high sensitivity ELISA (Quantikine, R\&D Systems Europe, Oxon, UK) with a lower limit of detection of $0.5 \mathrm{pg} / \mathrm{ml}$ and 0.156 $\mathrm{pg} / \mathrm{ml}$ respectively. Plasma CRP was measured by high sensitivity particle-enhanced immunonephelometry (Cardiophase; BN systems, Dade Behring, Newark, NJ, USA).

\section{Statistical analysis}

Normal distribution was assessed by Kolmogorov-Smirnov goodness of fit test and non-parametric data were natural log transformed or presented as median and interquartile range (IQR). The univariate correlation of biomarkers and depression and fatigue scores were examined by Spearman correlation. The difference in the mean of parametric variables was examined using the analysis of variance (ANOVA). The Mann-Whitney and Kruskal-Wallis tests were used to examine the difference in the median value of each biomarker in two groups or quartiles of either depression or fatigue respectively. The chi square $\left(x^{2}\right)$ test was used to examine the categorical association of systemic biomarkers and depression and fatigue. The multivariate linear and binary regression analyses were used to examine the association of factors with depression or fatigue. SPSS version 15 (SPSS Inc, USA) was used.

\section{Results}

We examined 120 patients with mainly moderate COPD (mean $\mathrm{FEV}_{1} \% 52.5$ (SD 18.5)), mean age was 66 years and women made up $38 \%$ of the sample. Patients with GOLD stage $2(60(50 \%))$ dominated the sample while patients with GOLD stage 1, 3 and 4 represented (6 (5\%), $38(32 \%)$ and $16(13 \%))$, respectively. Although the majority of the patients were ex-smokers (86 (71.7\%), there were 34 current smokers $(28.3 \%)$. The current smokers were slightly younger, half of them were women, and they had slightly worse airway obstruction, more fatigue, more depressive symptoms and less lean tissue. More demographic data are shown in table 1. The median (IQR) of BASDEC and CES-D scores were 3 (4.5) and 10 (12) respectively, and the mean (SD) MCFS was 24.8 (12.8) and the median (IQR) Borg scale at baseline and post-6MWT were 0.5 (2) and 2 (3.5) respectively.

There were mild to moderate intercorrelations between the systemic inflammatory biomarkers as shown in table 2 .

\section{Depression and systemic inflammation}

Univariate correlation analyses showed no statistically significant association between systemic inflammatory biomarkers and CES-D and BASDEC depression scores except for a weak correlation between TNF- $\alpha-\mathrm{R} 1$ and 
Table 1 Baseline characteristics of the sample; mean values and standard deviations are shown unless otherwise noted

\begin{tabular}{|c|c|c|c|c|}
\hline & All & $\begin{array}{l}\text { Ex- } \\
\text { smokers }\end{array}$ & $\begin{array}{l}\text { Current } \\
\text { smokers }\end{array}$ & $\begin{array}{l}P \text { - } \\
\text { value }\end{array}$ \\
\hline Number & 120 & $86(71.7 \%)$ & $34(28.3 \%)$ & \\
\hline Age, yrs & $66 \pm 6.7$ & $67 \pm 6.9$ & $64 \pm 6.6$ & 0.03 \\
\hline Females (\%) & $46(38 \%)$ & $30(35 \%)$ & $16(47 \%)$ & $0.4^{*}$ \\
\hline $\mathrm{FEV}_{1} \%$ & $\begin{array}{l}52.5 \pm \\
18.5\end{array}$ & $\begin{array}{l}53.5 \pm \\
18.5\end{array}$ & $47.8 \pm 17.7$ & 0.12 \\
\hline $\mathrm{PaO}_{2}(\mathrm{kPa})$ & $9.2 \pm 1.4$ & $9.1 \pm 1.1$ & $9.3 \pm 1.2$ & 0.4 \\
\hline $\mathrm{PaCO}_{2}(\mathrm{kPa})$ & $5.2 \pm .58$ & $5.1 \pm 0.5$ & $5.3 \pm 0.7$ & 0.05 \\
\hline MCFS & $\begin{array}{l}25.1 \\
\pm 12.5\end{array}$ & $23.9 \pm 12$ & $28 \pm 13.5$ & 0.11 \\
\hline CES-D Median (IQR) & $10(12)$ & $9(12)$ & $11(11)$ & $0.4 \#$ \\
\hline BMI $\left(\mathrm{kg} / \mathrm{m}^{2}\right)$ & $\begin{array}{l}27.5 \pm \\
5.8\end{array}$ & $27.9 \pm 5.5$ & $26.5 \pm 6.4$ & 0.22 \\
\hline FFMI $\left(\mathrm{kg} / \mathrm{m}^{2}\right)$ & $\begin{array}{l}17.8 \pm \\
3.1\end{array}$ & $18.3 \pm 3.2$ & $17.2 \pm 3.6$ & 0.09 \\
\hline $\begin{array}{l}\text { Pack/years Median } \\
\text { (IQR) }\end{array}$ & $40(25.8)$ & $38.3(31.1)$ & $41.9(22.5)$ & $0.8 \#$ \\
\hline
\end{tabular}

\# Mann-Whitney U Test; * $x^{2}$-Test; IQR = Interquartile Range; FEV $1 \%=$ Forced Expiratory Volume over 1 second of predicted; $\mathrm{PaO}_{2}=$ Arterial oxygen partial pressure; $\mathrm{kPa}=$ kilo Pascal; $\mathrm{PaCO}_{2}=$ Arterial carbon dioxide pressure; $\mathrm{MCFS}=$ Manchester COPD Fatigue Scale; CES-D = Centre for Epidemiologic Studies Depression Scale; BMI = Body Mass Index; FFMI = Fat-Free Mass Index

BASDEC score ( $r$ ho $=-0.2, \mathrm{p}=0.03$ ). We found no difference in the median of all biomarkers between symptomatically depressed and not depressed.

Using the BASDEC scores as the dependent variable, a multivariate linear regression analysis showed a positive association between TNF- $\alpha$ and depression scores (Beta $=0.26, \mathrm{p}=0.007$ ) as shown in table 3 (Module 1). The association remained unchanged after adjusting for TNF- $\alpha-R 1$ and TNF- $\alpha-R 2$ (Beta $=0.27, \mathrm{p}=0.005)$. TNF- $\alpha$ still had a positive correlation with depression (Beta $=0.23, \mathrm{p}=0.024)$ in the multivariate model after further adjusting for $6 \mathrm{MWD}, \mathrm{FEV}_{1} \%$, and pack/years, as shown in table 3 (Module 2); this model explained $15.6 \%$ of the variance in depression scores where TNF- $\alpha$

Table 2 Univariate (Spearman (rho)) correlations between inflammatory biomarkers

\begin{tabular}{lllll}
\hline & TNF- $\boldsymbol{\alpha}$ & CRP & TNF R1 & TNF R2 \\
\hline TNF- $\boldsymbol{\alpha}$ & 1 & & & \\
\hline CRP & 0.11 & 1 & & \\
\hline TNF- $\boldsymbol{\alpha}$ R1 & $0.368^{* *}$ & $0.285^{* *}$ & 1 & \\
\hline TNF- $\boldsymbol{\alpha}$ R2 & $0.282^{* *}$ & 0.104 & $.548^{* *}$ & 1 \\
\hline IL-6 & 0.114 & $0.449^{* *}$ & $.391^{* *}$ & $.199^{*}$ \\
\hline
\end{tabular}

** Correlation is significant at the 0.01 level (2-tailed).

* Correlation is significant at the 0.05 level (2-tailed).

CRP = C-reactive protein; IL- $6=$ Interleukin- 6 ; TNF- $\alpha=$ Tumor necrosis factor$\alpha$; TNF- $\alpha$ R1 $=$ Tumor necrosis factor- $\alpha$ receptor $1 ;$ TNF- $\alpha$ R2 $=$ Tumor necrosis factor- $\alpha$ receptor 2
Table 3 Multivariate linear regression modules for factors associated with depression

\begin{tabular}{llllll}
\hline Module $\mathbf{1}$ & \multicolumn{5}{c}{ Module $\mathbf{2}$} \\
\hline Variables & Beta & $\mathbf{p}$ & Variables & Beta & $\mathbf{p}$ \\
\hline TNF- $\alpha$ & 0.26 & 0.007 & TNF- $\alpha$ & 0.23 & 0.024 \\
\hline CRP & 0.07 & 0.5 & TNF- $\alpha-R 1$ & -0.13 & 0.3 \\
\hline TNF- $\alpha-R 1$ & -0.1 & 0.5 & TNF- $\alpha-R 2$ & -0.13 & 0.3 \\
\hline TNF- $\alpha-R 2$ & -0.2 & 0.2 & 6 MWD & -0.22 & 0.027 \\
\hline IL-6 & -0.2 & 0.1 & FEV $1 \%$ & 0.02 & 0.9 \\
\hline & & & Pack/years & -0.02 & 0.9 \\
\hline
\end{tabular}

*BASDEC depression score was the dependent variable

$\mathrm{CRP}=\mathrm{C}$-reactive protein; $\mathrm{FEV}_{1}=$ Forced Expiratory Volume over 1 Second; IL-6 $=$ Interleukin-6; $6 \mathrm{MWD}=6$ Minute Walk Distance; TNF- $\alpha=$ Tumor necrosis factor- $\alpha$; TNF- $\alpha$ R1 $=$ Tumor necrosis factor- $\alpha$ receptor $1 ;$ TNF- $\alpha$ R2 $=$ Tumor necrosis factor- $\alpha$ receptor 2 .

alone contributed with 5\%. Furthermore, adding the total Manchester COPD Fatigue Scale (MCFS) score, BMI and FFMI to the model did not change the findings; i.e., TNF- $\alpha$ still had a significant positive correlation with BASDEC depression score $($ Beta $=0.17 \mathrm{p}=$ 0.044).

For exploration, we selected higher cut-off points for each systemic biomarker to categorize the sample, and we found that the patients with higher TNF- $\alpha$ level $(>3$ $\mathrm{pg} / \mathrm{ml}, \mathrm{n}=7$ ) had higher mean CES-D depression score than the rest of the sample ( 15 vs $10.4, \mathrm{p}=0.03$ ) as shown in figure 1 . For BASDEC scores the differences were less obvious (5.4 vs $3.6, \mathrm{p}=0.2$ ). We found no statistically significant differences for CRP and IL-6.

\section{Fatigue and systemic inflammation}

We found no statistically significant correlation between total MCFS scores and any of the systemic biomarkers. Similarly, no univariate statistically significant correlation was found between systemic biomarkers and the physical, cognitive or psychosocial dimensions of MCFS ( $p>0.05$ for all correlations). Using categorical analyses, there was no statistically significant difference in the median of all biomarkers between the 4 fatigue quartiles. Similarly, we found no statistically significant difference in the median of the inflammatory biomarkers in quartiles of physical and cognitive.

Borg fatigue scores at baseline had a weak positive correlation with TNF- $\alpha$ and CRP (rho $=0.24, \mathrm{p}=0.01$, and $0.19, \mathrm{p}=0.05$, respectively). Similarly, Borg fatigue scores after $6 \mathrm{MWT}$ had a weak correlation with TNF- $\alpha$ only (rho $=0.23, \mathrm{p}=0.01$ ).

For further exploration, we selected higher cut-off points and found that the mean of the total and dimensional MCFS score of patients with higher TNF- $\alpha(>3 \mathrm{pg} / \mathrm{ml}, \mathrm{n}$ $=7$ ) was higher than the rest of the sample, but the differences did not reach statistical significance. A similar trend was seen for the mean fatigue score in Borg scale after 


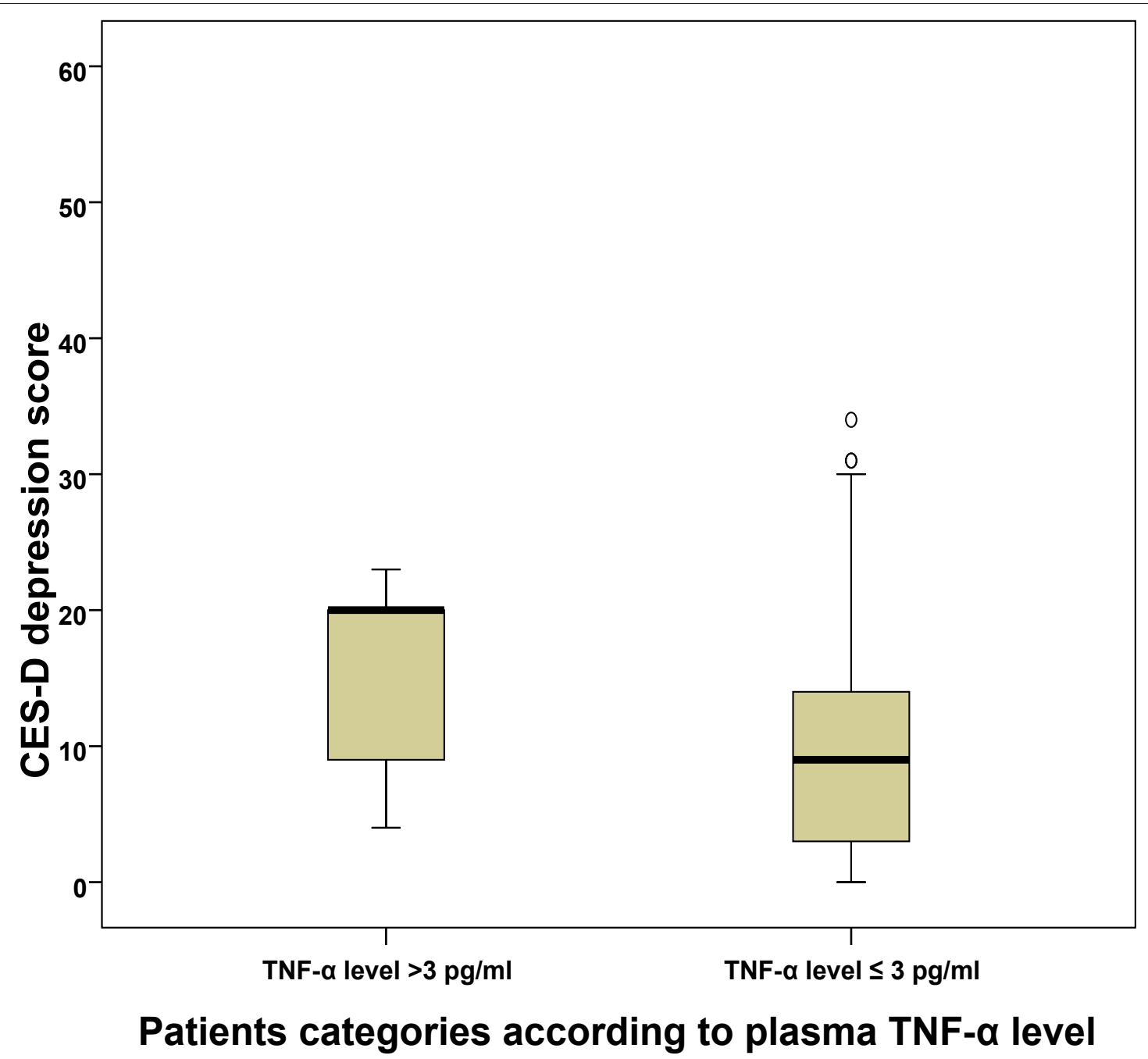

Figure 1 Mean CES-D depression scores in relation to plasma TNF- $\alpha$ level. CES-D = Centre for Epidemiologic Studies Depression Scale, TNF- $\alpha=$ Tumor necrosis factor- $\alpha$

6MWT (3.7 vs. 2.2, $\mathrm{p}=0.054)$. However, this correlation was not found in multivariate analyses.

\section{Discussion}

We explored the association between systemic inflammation and depression and fatigue using a range of inflammatory biomarkers, two depression scales and two fatigue scales in a cohort of 120 patients with clinically stable COPD. There were modest correlations between systemic inflammation and depression and fatigue. However, the association between TNF- $\alpha$ and depression remained significant even after adjusting for confounding factors in multivariate analyses. This finding was also consistently seen in further categorical analyses.

An association between systemic inflammation and depression could be the result of the effect of confounders. It has been suggested that both systemic inflammation and depression correlate with poor functional performance $[4,24]$, fatigue $[10,25]$, BMI $[24,26]$ and FFMI $[4,27]$. To explore the possibility of confounding as a result of these factors, we did different multivariate analyses. In a model with depression as the dependent variable, adjusting for the MCFS score, $6 \mathrm{MWD}, \mathrm{FEV}_{1} \%, \mathrm{BMI}$ and FFMI did not markedly change the association between TNF- $\alpha$ and depression and it remained statistically significant. The robustness of this association may reflect a true association as a result of the fact that COPD is principally a progressive inflammatory disabling disease [1] and that major depression or sub-threshold depressive symptoms are quite prevalent $[17,28]$ even in patients with moderate clinically stable COPD [4]. Therefore, it seems plausible that systemic inflammation is correlated with depression as suggested by Barns and Celli [13]. 
The mechanism behind this relationship could have a bidirectional nature [29] particularly in COPD. In fact, studies have shown that inflammatory cytokines had a direct effect on the central nervous system including the enhancement of negative moods [29-32]. On the other hand, depression was associated with increased plasma cytokines, and the production of pro-inflammatory cytokines was frequently seen in depression $[29,30]$. This could be clinically important given the chronic inflammatory progressive pattern of COPD, and opens the possibility of effective antidepressants having an effect on the inflammatory response system $[31,33]$ or effective anti-inflammatory therapy having an effect on depression, a major comorbidity in COPD.

We used our validated Manchester COPD-fatigue scale (MCFS) [7] to assess the association between systemic inflammation and fatigue and we found that patients with less fatigue had a tendency to have lower levels of TNF- $\alpha$. We found this for both the total and dimensional fatigue using the MCFS. Moreover, there was a weak association between the severity (intensity) of fatigue before and after exercise test with TNF- $\alpha$ and CRP but not with TNF- $\alpha$-Rs and IL-6. It has previously been reported that exhausted patients with CHD had higher levels of TNF- $\alpha$ and IL-6 (mean rank of TNF- $\alpha$ and IL- 6 values of exhausted vs not exhausted were 17.9 vs $12.3, \mathrm{p}=0.04$, and 17 vs $12, \mathrm{p}=0.06$, respectively) [10].

Even with the significant correlations reported, the small association between systemic inflammation and these systemic manifestations should be discussed. First, the sample of this study composed of mainly moderate COPD and a larger sample with a range of COPD severities would better explore this possible relationship. Secondly, we have chosen stable patients and the signal may be more apparent in frequent exacerbators or patients with major depression who are unlikely to be in this study population. For instance, a worse scenario would be expected had we looked at patients with less stable patients or even patients during exacerbation, given that others have found exacerbations are correlated with systemic inflammation [34], depression [19] and fatigue [25]. More studies, probably of longitudinal nature will be required to disentangle these associations.

We can not preclude that our findings may be affected by the variability in the measured biomarkers $[10,35,36]$. However, we measured a range of biomarkers that have been shown to be important in studying the morbidity and mortality in COPD [37], and we used several wellvalidated subjective and objective assessment tools. We applied strict inclusion criteria by excluding patients with diseases that may have a potential confounding effect. We made the effort to ensure that the blood samples were obtained carefully from clinically stable patients. For this purpose, we excluded patients with recent symptomatic coronary heart disease and patients with COPD exacerbations were either rescheduled or excluded.

\section{Conclusion}

In conclusion, our data indicate an association between TNF- $\alpha$ and two major co-morbidities in COPD; i.e., depression and fatigue. However, further studies are required to explore this subject and to tackle the biological roles of these biomarkers in relation to depression and/or fatigue.

\section{Abbreviations}

(BMI): Body Mass Index; (BODE): Multidimensional index ( $\mathrm{B}=$ Body mass index, $\mathrm{O}=$ Obstruction of air ways as measured by $\mathrm{FEV}_{1}, \mathrm{D}=$ Dyspnoea as measured by MRC scale, $E$ = Exercise capacity as measured by $6 \mathrm{MWT}$ ); (BASDEC): Brief Assessment Schedule Depression Cards; (CES-D): Centre for Epidemiologic Studies Depression Scale; (COPD): Chronic obstructive pulmonary disease; (CRP): C-reactive protein; (FFMI): Fat-Free Mass Index; $\left(\right.$ FEV $\left._{1}\right)$ : Forced Expiratory Volume in 1 Second; (FVC): Forced Vital Capacity; (GOLD): Global Initiative for Chronic Obstructive Lung Disease; (IL-6): Interleukin-6; (IQR): Interquartile range; (L): Litre; (MRC): Medical Research Council Scale; (6MWD): 6 Minute Walk Distance; (6MWT): 6 Minute Walk Test; $(\mathbf{m})$ : Meter; (Q): Quartile; (TNF-a): Tumor necrosis factor-a; TNF-a R1: Tumor necrosis factor-a receptor1; TNF-a R2: Tumor necrosis factor-a receptor2.

\section{Author details}

${ }^{1}$ University Of Manchester, Medicines Evaluation Unit, NIHR Translational Research Facility, Manchester Academic Health Sciences Centre, University Hospital Of South Manchester Foundation Trust, Wythenshawe, Manchester, UK. ${ }^{2}$ The Medical Statistics Department, Education and Research Centre, South Manchester University Hospital, Wythenshawe, The University of Manchester, UK. ${ }^{3}$ Department of Cardiology and Respiratory Medicine, Hvidovre University Hospital, Hvidovre, Denmark.

\section{Authors' contributions}

KA participated in the study design and data collection and performed all the statistical analyses and wrote the manuscript. UK participated in data collection and analysis. RD participated in data collection and analysis. JM participated in data analysis and manuscript review. DS participated in the study design, data analysis and manuscript review. JV participated in the study design, data analysis and manuscript writing and review. All authors read and approved the final manuscript.

\section{Competing interests}

The authors declare that they have no competing interests.

Received: 9 November 2010 Accepted: 5 January 2011

Published: 5 January 2011

\section{References}

1. GOLD Scientific Committee: Global strategy for the diagnosis, management and prevention of chronic obstructive pulmonary disease. GOLD Scientific Committee [http://www.goldcopd.org/], Retrieved on 12/02/ 2009.

2. Agusti AG: Systemic effects of chronic obstructive pulmonary disease. Proc Am Thorac Soc 2005, 2(4):367-70, discussion 371-2.

3. Fabbri LM, Luppi F, Beghe B, Rabe KF: Complex chronic comorbidities of COPD. Eur Respir J 2008, 31(1):204-12.

4. Al-shair K, Dockry R, Mallia-Milanes B, Kolsum U, Singh D, Vestbo J: Depression and its relationship with poor exercise capacity, BODE index and muscle wasting in COPD. Respir Med 2009, 103(10):1572-9.

5. Ng TP, Niti M, Tan WC, Cao Z, Ong KC, Eng P: Depressive symptoms and chronic obstructive pulmonary disease: effect on mortality, hospital 
readmission, symptom burden, functional status, and quality of life. Arch Intern Med 2007, 167(1):60-7.

6. Theander K, Unosson M: Fatigue in patients with chronic obstructive pulmonary disease. J Adv Nurs 2004, 45(2):172-7.

7. Al-Shair K, Kolsum U, Berry P, Smith J, Caress A, Singh D, et al: Development, dimensions, reliability and validity of the novel Manchester COPD fatigue scale. Thorax 2009, 64(11):950-5.

8. Breslin E, van der Schans C, Breukink S, Meek P, Mercer K, Volz W, Louie S: Perception of fatigue and quality of life in patients with COPD. Chest 1998, 114:958-964

9. Steptoe A, Kunz-Ebrecht SR, Owen N: Lack of association between depressive symptoms and markers of immune and vascular inflammation in middle-aged men and women. Psychol Med 2003, 33(4):667-74.

10. Appels A, Bar FW, Bar J, Bruggeman C, de Baets M: Inflammation, depressive symptomtology, and coronary artery disease. Psychosom Med 2000, 62(5):601-5.

11. Miller GE, Freedland KE, Duntley S, Carney RM: Relation of depressive symptoms to C-reactive protein and pathogen burden (cytomegalovirus, herpes simplex virus, Epstein-Barr virus) in patients with earlier acute coronary syndromes. Am J Cardiol 2005, 95(3):317-21.

12. Watz H, Waschki B, Boehme C, Claussen M, Meyer T, Magnussen H: Extrapulmonary effects of chronic obstructive pulmonary disease on physical activity: a cross-sectional study. Am J Respir Crit Care Med 2008, 177(7):743-51.

13. Barnes PJ, Celli BR: Systemic manifestations and comorbidities of COPD. Eur Respir J 2009, 33(5):1165-85.

14. GOLD Scientific Committee: Global strategy for the diagnosis, management and prevention of chronic obstructive pulmonary disease. GOLD Scientific Committee [http://www.goldcopd.org/, Retrieved on 12/01/ 2006.

15. Adshead F, Cody DD, Pitt B: BASDEC: a novel screening instrument for depression in elderly medical inpatients. BMJ 1992, 305:397.

16. Radloff LS: The CES-D scale: A self-report depression scale for research in the general population. Appl Psychol Measur 1977, 1:385-401.

17. Yohannes AM, Baldwin RC, Connolly MJ: Depression and anxiety in elderly outpatients with chronic obstructive pulmonary disease: prevalence, and validation of the BASDEC screening questionnaire. Int I Geriatr Psychiatry 2000, 15:1090-6.

18. Garrod R, Marshall J, Barley E, Jones PW: Predictors of success and failure in pulmonary rehabilitation. Eur Respir J 2006, 27(4):788-94.

19. Quint JK, Baghai-Ravary R, Donaldson GC, Wedzicha JA: Relationship between depression and exacerbations in COPD. Eur Respir J 2008, 32(1):53-60.

20. Borg GA: Psychophysical bases of perceived exertion. Med Sci Sports Exerc 1982, 14(5):377-81.

21. Miller MR, Crapo R, Hankinson J, Brusasco V, Burgos F, Casaburi R, Coates A, Crapo $R$, Enright $P$, van der Grinten CP, Gustafsson P, Jensen R, Johnson DC, MacIntyre N, McKay R, Navajas D, Pedersen OF, Pellegrino R, Viegi G, Wanger J: Standardisation of Spirometry "ATS/ERS Task Force: Standardisation of Lung Function Testing". Eur Resp J 2005, 26:319-338.

22. American Thoracic Society: ATS Statement: Guidelines for the Six-Minute Walk Test. Am J Respir Crit Care Med 2002, 166:111-7.

23. Jones PW, Quirk FH, Baveystock CM, Littlejohns P: A self-complete measure of health status for chronic airflow limitation. The St. George's Respiratory Questionnaire. Am Rev Respir Dis 1992, 145(6):1321-7.

24. Broekhuizen R, Wouters EF, Creutzberg EC, Schols AM: Raised CRP levels mark metabolic and functional impairment in advanced COPD. Thorax 2006, 61(1):17-22.

25. Baghai-Ravary R, Quint JK, Goldring JJ, Hurst JR, Donaldson GC, Wedzicha JA: Determinants and impact of fatigue in patients with chronic obstructive pulmonary disease. Respir Med 2009, 103(2):216-23.

26. Chavannes NH, Huibers MJ, Schermer TR, Hendriks A, van Weel C, Wouters EF, van Schayck CP: Associations of depressive symptoms with gender, body mass index and dyspnea in primary care COPD patients. Fam Pract 2005, 22(6):604-7.

27. Di Francia M, Barbier D, Mege $J \mathrm{~L}$, Orehek J: Tumor necrosis factor-alpha levels and weight loss in chronic obstructive pulmonary disease. Am J Respir Crit Care Med 1994, 150(5 Pt 1):1453-5.
28. Yohannes AM, Baldwin RC, Connolly MJ: Prevalence of sub-threshold depression in elderly patients with chronic obstructive pulmonary disease. Int J Geriatr Psychiatry 2003, 18(5):412-6.

29. Kiecolt-Glaser JK, Glaser R: Depression and immune function: central pathways to morbidity and mortality. J Psychosom Res 2002, 53(4):873-6.

30. Connor TJ, Leonard BE: Depression, stress and immunological activation: the role of cytokines in depressive disorders. Life Sci 1998, 62(7):583-606

31. Borson S, Scanlan J, Friedman S, Zuhr E, Fields J, Aylward E, Mahurin R, Richards T, Anzai Y, Yukawa M, Yeh S: Modeling the impact of COPD on the brain. Int J Chron Obstruct Pulmon Dis 2008, 3(3):429-34.

32. Anisman H, Hayley S, Turrin N, Merali Z: Cytokines as a stressor: implications for depressive illness. Int I Neuropsychopharmacol 2002, 5(4):357-73.

33. Sluzewska A, Rybakowski JK, Laciak M, Mackiewicz A, Sobieska M, Wiktorowicz K: Interleukin-6 serum levels in depressed patients before and after treatment with fluoxetine. Ann N Y Acad Sci 1995, 762:474-6.

34. Hurst JR, Donaldson GC, Perera WR, Wilkinson TM, Bilello JA, Hagan GW, Vessey RS, Wedzicha JA: Use of plasma biomarkers at exacerbation of chronic obstructive pulmonary disease. Am J Respir Crit Care Med 2006, 174(8):867-74

35. Garrod R, Marshall J, Barley E, Fredericks S, Hagan G: The relationship between inflammatory markers and disability in chronic obstructive pulmonary disease (COPD). Prim Care Respir J 2007, 16(4):236-40.

36. Kolsum U, Roy K, Starkey C, Borrill Z, Truman N, Vestbo J, Singh D: The repeatability of interleukin-6, tumor necrosis factor-alpha, and C-reactive protein in COPD patients over one year. Int I Chron Obstruct Pulmon Dis 2009, 4(1):149-56.

37. Gan WQ, Man SF, Senthilselvan A, Sin DD: Association between chronic obstructive pulmonary disease and systemic inflammation: a systematic review and a meta-analysis. Thorax 2004, 59(7):574-80.

doi:10.1186/1465-9921-12-3

Cite this article as: Al-shair et al: Biomarkers of systemic inflammation and depression and fatigue in moderate clinically stable COPD.

Respiratory Research 2011 12:3.

\section{Submit your next manuscript to BioMed Central and take full advantage of:}

- Convenient online submission

- Thorough peer review

- No space constraints or color figure charges

- Immediate publication on acceptance

- Inclusion in PubMed, CAS, Scopus and Google Scholar

- Research which is freely available for redistribution

Submit your manuscript at www.biomedcentral.com/submit
C Biomed Central 